\title{
Supervivencia de la nobleza indígena en el siglo XVI
}

Juan Manuel Pérez Zevallos

CIESAS

$\mathrm{E}$ 1 estudio sobre los cambios y continuidades del mundo indígena ha sido uno de los temas preferidos por historiadores y antropólogos. Unos y otros han hecho hincapié en algunos elementos o aspectos que relacionaron al indígena con las instituciones coloniales, con el sistema colonial en su conjunto. ${ }^{1}$

A partir de la irrupción española, los procesos sociales, económicos, políticos y religiosos que se habían dado en Mesoamérica se rompieron y se entabló una relación asimétrica entre co-

1 Gibson, Aztecas, 1980; Gerhard, "Evolución", 1975 y "Continuity", 1975; Carrasco, "Transformación", 1975; Spalding, "Resistencia", 1981; Kellog, "Supervivencia", 1984; Farriss, Maya, 1984 y García Martínez, Pueblos, 1987. lonizados y colonizadores. Se sucedieron, de una manera vertiginosa, cambios en la sociedad indígena y ésta, para sobrevivir, tuvo que buscar y desarrollar complejas redes de relaciones sociales, políticas y económicas.

Es sorprendente ver cómo en pocos años el poder del Huey Tlahtocayo (la Triple Alianza) se fragmentó y a consecuencia de ello se dio la ruptura del orden prehispánico y la destrucción de las unidades políticas mayores. La relación de redistribución, que mantuvo a los tlahtoque (señores o caciques) y sus tlahtocayo (señoríos) con sus dependencias, quedó trunca. El principio de reciprocidad entre los segmentos sociales, que intervenían no sólo en la producción, sino también en el reparto de productos y en el acceso y 


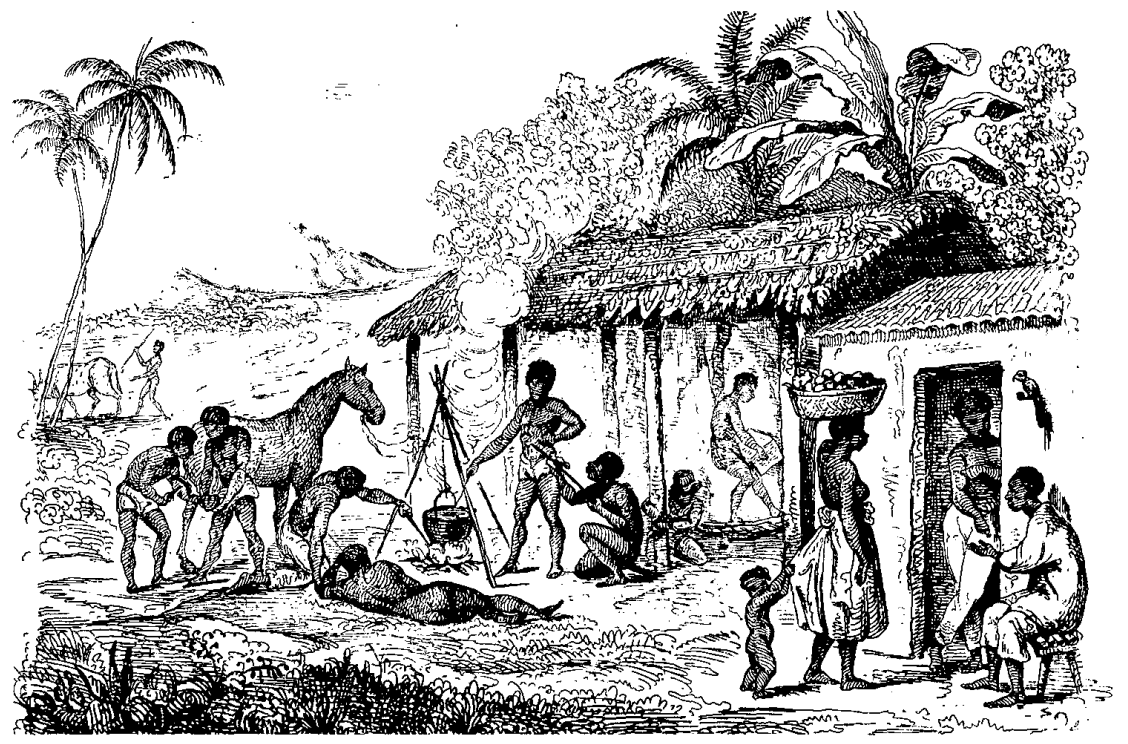

rotación de la tierra se había perdido. Y al desaparecer éstos, el Estado colonial simplificó la compleja jerarquía social prehispánica estableciendo, inicialmente, la separación entre "principales" y "macehuales", para posteriormente homogeneizar e integrar a toda la sociedad indígena dentro de la categoría de "indio". ${ }^{2}$ El sistema colonial removió del poder al Huey tlahtoani y reconoció a los demás tlahtoque de cada pueblo, respetó su propia organización tradicional, redujo la jurisdic.

2 Esta simplificación la observamos en los trabajos sobre el México colonial, aunque recientemente el trabajo de Serge Gruzinski, Colonisation, 1988, advierte e insiste en el mosaico de culturas. Sobre el concepto del indio véase Bonfil, "Concepto", 1972. ción política de éstos, propició el surgimiento de nuevos centros de poder y provocó la rápida separación de algunos sujetos de sus cabeceras.

Con la encomienda, a la población indígena se le impusieron nuevos criterios territoriales, nuevos lazos de sujeción y con ello se sucedieron varios problemas entre los pueblos. Estos cambios ocurrieron de una manera muy acelerada en los lugares apartados del centro de México. Años más tarde, las formas de gobierno prehispánico dieron paso al gobierno indigena: el cabildo que se creó y desarrolló a partir de 1535-1536 aproximadamente, $y$ bajo la tutela de la corona, tuvo una jurisdicción limitada, una autonomía relativa.

Los primeros cincuenta años de vi- 
da colonial, si bien provocaron cambios en la vida indígena, estuvieron también marcados por el esfuerzo de la sociedad indigena en general por comprender a la nueva sociedad. ${ }^{3}$

Las distintas administraciones que se sucedieron hasta antes de 1568 reconocieron a los tlahtoque como caciques, al otorgarles participación en la administración colonial, respeto al derecho tradicional de sus tierras y al ser encargados de vigilar el cumplimiento del pago de los tributos y el control de los macehuales. ${ }^{4}$

A partir de 1568, en el espacio colonial novohispano se dio una "vigorosa reorganización" de la administración. ${ }^{5}$ Muchos temas estuvieron en discusión a la puerta del decenio de 1570: el servicio personal, el repartimiento, la libertad de movimiento de los indige. nas, la retasación de los tributos, el abuso de los españoles, etcétera.

Lo que me interesa de manera especial, es ver cómo la nobleza indigena, la de los altepetl o pueblos, ${ }^{6}$ logró resistir y adaptarse a la vida colonial. ${ }^{7}$

3 Véase el trabajo de Ruiz Medrano sobre los gobiernos de la Segunda Audiencia, y del virrey Antonio de Mendoza, Gobierno, 1991.

4 Véase el trabajo de Saravia, Velasco, 1978.

5 Véase el trabajo de García-Abasolo sobre el gobierno del virrey Martín Enríquez y la reforma de 1568, Enriquez, 1983.

6 "Lo que se llama pueblo de indios, o simplemente pueblo, es la derivación colonial del alte petl prehispánico, y debe entenderse como un elemento básico o fundamental en la organización política indigena de toda Mesoamérica, o por lo menos en la de los pueblos nahuas y los influidos por ellos." García Martínez, Pueblos, 1987 , p. 21.

$7 \mathrm{~A}$ pesar de que algunos investigadores han señalado que los indios asimilaron rápidamente muchos rasgos de la vida española y que por ello
Creo que los caciques tuvieron que ha. ber comprendido los efectos destructores del sistema que se les impusieron, se dieron cuenta de que su espacio sería transformado, que su poder se reduciría y que sus tierras iban a ser expropiadas. Sin embargo, esta comprensión debió ser lenta pues el sistema colonial les abrió los espacios, siguieron siendo tlahtoque de sus pueblos, lograron ser reconocidos por los españoles, porque muchos fueron gobernadores en los cabildos, gobernadores foráneos de otros pueblos y jue. ces de residencia en pueblos de indios, etc. Y tal vez, lo más importante fue que entendieron su papel de intermediarios entre su pueblo y el nuevo Estado. Los tlahtoque y teteuhtin (señores principales) rápidamente aprovecharon esta situación para mantener su poder, antepusieron el título de don a sus nombres cristianos, vistieron a la española, portaron daga y espada y montaron a caballo. ${ }^{8}$ Esto, a mi modo de ver, no fue sino una manera de de. mostrar su capacidad de negociación, de hacer valer su posición de nobles y de lograr un espacio dentro del aparato colonial. Es decir, buscaron nuevas relaciones y alianzas que les permitieran una mejor ubicación en la sociedad, lo cual podría entenderse como una me-

muchos caciques y principales se hispanizaron, considero que ya es tiempo de replantear estas apreciaciones en el sentido de que sólo inmersos en el sistema colonial podían preservar las tradiciones culturales de su sociedad. Spalding, "Resistencia", 1981, p. 5. Gibson, Aztecas, 1980, p. 413.

${ }^{8}$ En los ramos de Indios y Mercedes del Archivo General de la Nación hay muchas referencias a este asunto. 
jor manera de resistir la presión colonizadora.

A pesar de lo anterior, debo señalar que, para la nobleza mexica, la situación no fue del todo halagüeña. El descabezamiento de los tlahtoque, sucesores de Moctezuma, había ocasionado un profundo cambio en las relaciones de poder indígena. La imagen de un nuevo poder, el español, representado en la figura del rey, se fue impo. niendo y la legitimidad de que gozaban los nobles mexicas se resquebrajó; así lo manifestaron hacia 1574: "Los pueblos vecinos y comarcanos a México, ansí como dejaron de reconocer a los mexicanos por señores como solían, ansí también se les alzaron con tierras y posesiones que tenían en las dichas comarcas." 9

Los pueblos indígenas sólo reconocieron a sus señores particulares, a los de cada pueblo, "y ahora [los indios principales y naturales de la ciudad de México] no tienen provincia ninguna sujeta, por que todas se han sustraído, y cada una se gobierna y está por sín.10

El desconocimiento del poder mexica implicó, entre otras cosas, que el tributo que pagaban pasara a manos de la corona y de sus señores particulares; así lo advertian los frailes agustinos en 1554 de la siguiente manera:

En lo que toca al señor universal ya ha cesado y casi de esto no hay memoria,

9 "Memorial de las cosas en que los indios principales y naturales de la ciudad de México pedimos y suplicamos a su majestad el rey don Felipe, nuestro señor sea servido de mandarnos desaparezcan" (9 mar. 1574), Códice Mendieta, 1971, vol. I, p. 184-186.

10 Ibid., vol. I, p. 184. porque no hay señor universal sino en su majestad, y los pueblos están o en su corona real o en encomienda de españoles, solamente tienen en cuenta con el señor particular:11

El reclamo de los principales y naturales mexicas no era sólo por el desconocimiento de sus antiguos señoríos, sino también por el abuso y creciente poder de los españoles que les habían hecho a un lado porque,

después los españoles se alzaron con todas las tierras de la ciudad y las han repartido entre sí, de manera que los naturales vecinos de la ciudad de México, que debían ser señores de toda la tierra, han quedado sin vasallo ninguno y sin tierras y posesiones, si no es aiguna miseria que algunos tienen, $y$ aun de sus casillas en que quedaron los han ido y van arrendando y echando poco a poco los españoles. ${ }^{12}$

No sólo les fueron expropiadas sus tierras y macehualtin, sino que el ejer-

11 "Parecer de la Orden de San Agustín sobre los señores y tributos de los indios, $1554^{\prime \prime}, \mathrm{Ca}$ rrasco, "Relaciones" , 1967, p. 123. En ese mismo año el fraile Agustín Nicolás de San Vicente señalaba, "porque como los pueblos están repartidos en diversas personas, como en la corona real y encomenderos, han ya perdido aquel reconocimiento del señor universal". "Parecer de fray Nicolás de San Vicente Paul, de la orden de San Agustín, sobre el modo que tenian de tributar los indios en tiempo de la gentilidad. Mextitlán" (25 agosto 1554), Del Paso y Troncoso, Epistolarto, 1939-1942, vol. xvI, 59.

12 "Memorial de las cosas", Codice Mendieta, 1971, vol. I, p. 184-186. En el Archivo General de Notarías se encuentran los registros de las ventas de tierras que realizaron muchos indios. Esto lo apunta sobre todo el notario Antonio Alonso, 2, Archivo General de Notarias. 
cicio del poder en que fincaban su permanencia en el sistema colonial les había sido quitado; exigían pues el privilegio del cual gozaban en las primeras décadas de la vida colonial y señalaban,

porque los señores lo tenían todo en concierto y policía a su modo, como queda dicho, que para ellos era muy bueno, y no había la confusión que hay después que esto ha faltado, y todo se hacía con menos vejación, y tenían cuenta con los tributos e con hacer labrar las sementeras y usar los oficios, y con recoger la gente que se repartía para servir los españoles, y se excusaban los robos y vejaciones que ahora hay en todo, e tenían cuenta con que acudiesen a la doctrina e al sermón y a misa, y en illes a la mano en sus vicios y borracheras, $y$ todo ha cesado e anda confuso, sin orden y sin concierto. 13

La decadencia del poder mexica no fue exclusiva de este grupo, también afectó a los señores particulares y prin. cipales, como señala el oidor Vasco de Puga hacia 1564, "que desta cuenta y visita que se cometió al dicho doctor Vasco de Puga se sigue contarse los principales y gobernador [...] y se les quita su nobleza a los que lo son y a los que nurica fueron tributarios los hacen". ${ }^{14}$

La corona contaba con un proyecto enmarcado en una ofensiva generalizada contra la población nativa, sobre todo durante la década de 1560 . No

13 Zorita, Breve, 1974, p. 99

14 "Carta al rey, del doctor Vasco de Puga, oidor de la Audiencia de México, sobre las tasaciones de tributos que hizo en algunos pueblos. Suchimilco" (28 febrero 1564), Del Paso y 'Troncoso, Eptstolarto, 1939-1942, vol. x, p. 34. olvidemos que en esos años se dio la ruptura del proyecto de los frailes con el de la corona. Un proyecto más demandante de recursos económicos, reflejado en la visita de Gerónimo de Valderrama en 1563-1565, obligó a los señores y principales de las ciudades más importantes de Nueva España a expresarse hacia 1570 ,

porque los animales vemos que son tratados mejor que nosotros [...] y nosotros estamos vejados peor que los caballos y bueyes, $y$ aun los esclavos son y parecen libres y sin trabajo y con todo regalo, y nosotros con nuestros macehuales más parecemos esclavos que libres vasallos de vuestra majestad, esto pensamos que lo hacen los dichos españoles a fin para que todos nosotros acabemos y fenezcamos, y no haya más memoria de nosotros. 15

Esto no es sino el ref lejo de la ruptura del antiguo orden, el prehispánico. Los españoles desconocieron el poder de los antiguos tlahtoque de la Triple Alianza, y aun cuando resaltaron el papel de los señores locales, éstos no se percataron de que la ofensiva no era sólo contra la nobleza mexica, sino contra toda la población indígena, que de una manera paulatina pero efectiva se vio arrinoonada en el sistema colonial.

A pesar de este panorama, el poder de los señores indígenas continuó,

15 Scholes y Adams (comps.), Cartas, 1961. "Carta de los señores y principales de las provincias y ciudades de la Nueva España más principales, para el rey don Felipe nuestro señor, en que piden ser desagraviados de las cosas aquí conten:das", Codice Mendieta, 1971, vol. I, pp. 128-13 (Centro de Estudios Históricos, 6). 
aunque mermado, durante el siglo XVI. La legislación española "no pudo borrar las diferencias provinciales y locales, las superviviencias del pasado, los privilegios y las arbitrariedades" ${ }^{16}$ En todo esto, el poder de los indígenas se debió, en buena medida, a la alianza que lograron con los frailes y éstos, a su vez, con el Estado colonial. Sin embargo, la participación que tuvo la nobleza en la administración colonial como jueces, gobernadores y oficiales de sus cabildos fue efímero. La intención de la corona fue individualizar a los pue. blos y otorgarles autonomía jurídica, hecho que acarreó un largo proceso de desestructuración. Los vínculos de reciprocidad y redistribución, en otro tiempo sustento de la Triple Alianza, se habían roto.

\section{DE GRANDES SEÑORES A POBRES MACEHUALES}

Para mediados del siglo xvi encontramos opiniones opuestas sobre el papel desempeñado por los caciques y principales en sus pueblos. Por un lado, el arzobispo de México Alonso de Montúfar señaló en 1554 que los caciques, gobernadores y principales tenían a los macehuales "más avasallados y cautivos que los cautivos que están en Argel" por lo que era necesario que "sean libertados [de] tan grande tiranía y opresiones como padecen de los caciques y principales ${ }^{n} .{ }^{17} \mathrm{Y}$ por otro lado,

16 Rosenblat, Poblact6n, 1967, p. 68.

17 "Carta del arzobispo de México al Consejo algunos frailes señalaban el debilitado poder de los señores, como lo refiere en su parecer fray Nicolás de San Vi. cente:

Y agora, como los habemos quitado los esclavos, quedan los pobres señores más pobres que los pobres macehuales, y no dejaré aquí de decir lo que por mis propios ojos he visto: que el señor universal de Mestitlán vi en su mismo pueblo ir con su coa a labrar su tierra, como el más pobre macehual del pueblo, y en verlo, como le topé, se me rajaron los ojos de agua, que apenas le podía ha. blar. 18

La corona debía limitar el poder y privilegios de que gozaban los señores. Años después, en 1563, Martín Cortés corroboraba que los caciques "tienen tiranizados, [y] usurpados [a] los indios", ${ }^{19}$ y añadió que era conveniente "remediarse en esta tierra el robo y dominio questos principales tienen sobre los macehuales". ${ }^{20}$ Esta situación de descrédito de los nobles empujó a la administración colonial a que se hiciera un recuento de la nobleza indígena,

de Indias sobre las vejaciones que sufrían los indios de sus caciques y principales" (30 noviembre 1554), Del Paso y Troncoso, Epistolario, 1939-1942, vol. vi, pp. 295-297.

18 "Parecer de fray Nicolás de San Vicente" (25 agosto 1554), Del Paso y Troncoso, Epistolarto, 19391942, vol. XVI, p. 58.

19 "Carta de D. Martín Cortés, segundo Marqués del Valke, al rey D. Felipe II, sobre los repartimientos y clases de tierras de Nueva España" (10 octubre 1563), Pacheco, Cárdenas, Torres, Colección, 1864-1884, p. 448.

20 "Carta de D. Martin Cortés" (10 octubre 1563), Pacheco, Cárdenas, Torres, Colección, 1864-1884, p. 449. 
pues para esos años muchos macehualtin habían adquirido el estatus de principales a través del cabildo o por imposición muchas veces de los encomenderos. Así lo refiere el oidor Alonso de Zorita:

No se había introducido vara de alcalde, ni gobernador ni alguacil, que ha sido la causa de abatir y deshacer los señores, como también lo ha sido haberlos quitado por su propia voluntad en los tributos y servicios personales que les pedían: y ponían un macehual que no hacía más que lo que ellos querian; y lo mesmo han hecho los caciques, que eran hombres que tenían los encomen. deros puestos en sus pueblos para hacer dar el servicio cada día, e arrendarios a otros, y enviar gente a las minas y hacer recoger los tributos y molestar en cuan. to podían pensar a los señores y a todo el común del pueblo; y quitaban y ponían señores con muy gran libertad todas las veces que se les antojaba. ${ }^{21}$

La emergencia de un nuevo tipo de "nobles", causantes de la sobreexplotación de los macehualtin, llevó a los franciscanos a salir en defensa de los auténticos nobles y a opinar ante el rey en 1574:

Debe mandar V.M. que se haga inquisición de los caciques que eran señores naturales, y mandar que éstos y no otros sean señores en sus pueblos, y que ningún español tenga autoridad de quitarlo y poner otro, pues son legítimos señores; y en esto hay gran desorden, que hacen señor a quien piensan que paga. rá mejor el tributo, allende del cual, al. gunos destos caciques postizos roban

${ }^{21}$ Zorita, Breve, 1974, pp. 92-93. los pueblos con otras sacaliñas para sí y para sus amos, y no es razón que fuera del tributo que la tasa les manda llevar reciban los presentes que reciben. ${ }^{22}$

Esta situación, sin embargo, ya había sido referida por Martín Cortés, quien advirtió que la voracidad de encomenderos y españoles, así como de los frailes y corregidores, había propiciado estos desajustes en los pueblos de indios:

Y esto por favor de los frailes e de los corregidores que residian en los lugares, que por parecelles hábiles, los hacían alcaldes y gobernadores $y$ alguaciles, $y$ en teniendo un indio un cargo destos de mandar, aunque fuese macegual, luego se hacía principal, aunque antes era macegual, y el otro año los que tomaban a elegir por alcaldes hacían lo mesmo. Y así vienen a haber tantos principales destos, ques casi la cuarta parte de la tierra, y éstos como tenían cargo de jus ticia y de mandar, usurpaban tierras de los tributarios, diciendo que eran de su patrimonio, y ponían en ellas indios renteros, que acá llaman maeques, y éstos les pagaban su tributo conforme a como se concertaban con ellos. ${ }^{23}$

Ante el creciente número de principales advenedizos, el mismo Martín Cortés proponía en su carta al rey:

y para esto me parece que debe V.M. mandar que se averigüe con la más ver-

22 "De fray Francisco de la Parra al Empera. dor" (febrero 1574), García Icazbalceta, (ed.) Codice Franctscano, 1941, p. 179.

23 "Carta de D. Martín Cortés" (10 octubre 1563), Pacheco, Cárdenas, Torres, Colecclón, 1864 -1884, p. 448. 


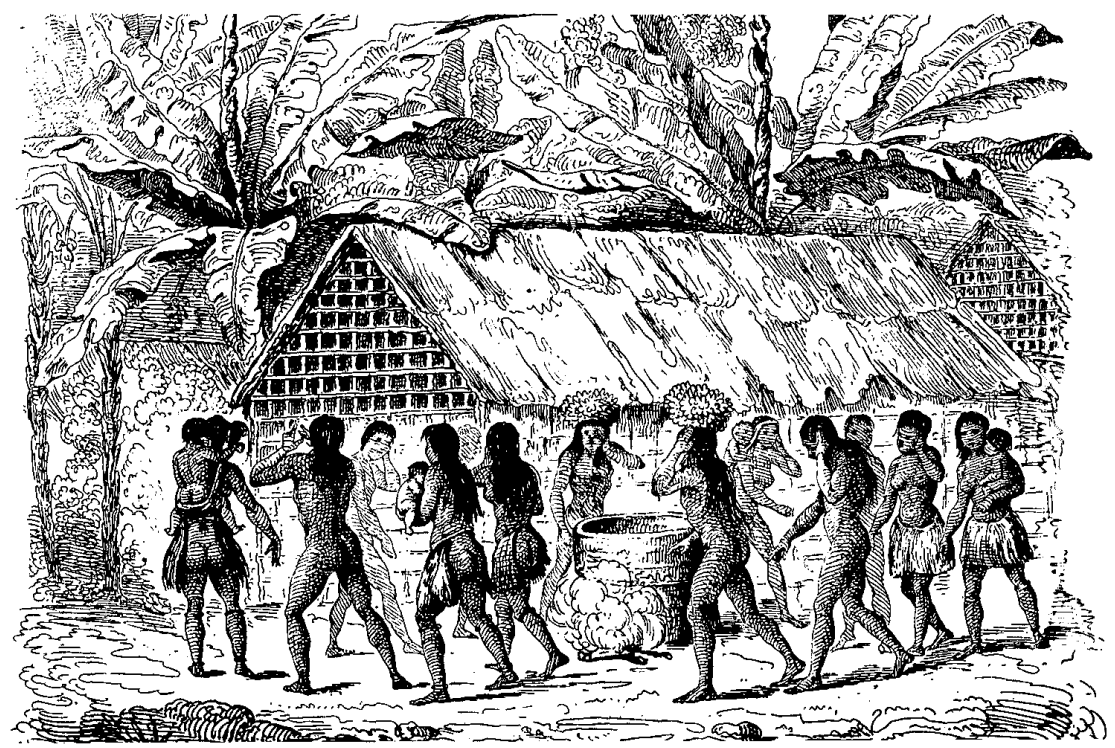

dad que se pudiere, quiénes son los principales antiguos que hay en cada lugar y que todos se pongan en un padrón [...] y que el qué no se averiguare ser principal y descender de antiguos principales, que no lo sea, porque en esta Nueva España, después que se ganó, se han muerto los más señores principales y naturales que había sin dejar sucesores, y se han hecho mandones y principales otros muchos que no les venia de derecho. 24

La situación no era muy clara para los nobles indígenas. Un creciente grupo de macehuales usurpaban los puestos de los señores y se hacían recono-

24 "Carta de D. Martín Cortés" (10 octubre 1563), Pacheco, Cárdenas, Torres, Coleccíon, 1864-1884, p. 449. cer como tales. Los partidarios de los indios opinaron, como lo hizo el oidor Zorita, que:

todos los señores, así supremos como inferiores, caciques y principales, están tan pobres, que no tienen qué comer, y están desposeídos de sus señorios, tierras y renteros y mayeques, y una de las causas que los han deshecho ha sido haberlos quitado el nombre de señores y haberlos hecho gobernadores [pues fácilmente ponían en su lugar a un mace. hual] todos están desposeídos y hechos tributarios y no les vale decir que son libres de tributo. 25

O como señala el franciscano Gerónimo de Mendieta en 1562

25 Zorita, Breve, 1974, p. 154. 
Paréceme que es razón se tenga cuenta con los señores naturales y legítimos, que (según dicen) estan desposeídos de sus señoríos. No me quiero meter más en esta materia [...] ni quiero tampoco tocar el señorío universal de la tierra [...] mas trato de los señores particulares, en cuanto a ser señores de sus indios y pue. blos los que antiguamente los poseían, porque pienso que algunos están expe. lidos y aún no sé si vueltos macehuales o tributarios y otros, ya que se les da alguna miseria, es por título de goberna. ción, de manera que quítales de ella se quedan en buenas noches. 26

La visión que nos transmite Mendieta de la situación de los nobles indige. nas es clara, eran hombres sin tierras, sin vasallos a quien gobernar, muchos de ellos ya se habían vuelto tributarios y por tanto macehuales. Una creciente uniformización de la sociedad indígena estaba en marcha.

Una de las instituciones, impuesta por el Estado colonial, para limitar el poder de los tlahtoque fue el cabildo. Este tipo de gobierno paralelo al poder tradicional no sólo circunscribió la participación de los señores, sino que también resquebrajó la organización de los pueblos. Las autoridades coloniales ya no reconocieron a los thahtoque, sus interlocutores fueron el gobernador, alcaldes y regidores. Este hecho no pasó inadvertido para la nobleza indígena pues, a pesar de todo, lograron controlar los cargos del cabildo, unas veces gracias a sus relaciones de parentesco y otras influyendo en la elección de los representantes. Pero

26 García Icazbalceta (comp.), Reltgiosos, 1941, pp. 23-24.

SUPERVIVENCIA DE LA NOBLEZA INDÍGENA los macehuales vieron también, en el cabildo, un nuevo escenario de participación, así como la posibilidad de alcanzar un nuevo estatus. ${ }^{27}$

La situación en aquellos años distó mucho de ser la mejor para la población indígena. Sucesivas pestes y enfermedades la habían diezmado de una manera irreversible, principalmente las de $1548,1559,1563-1564,1576$ $1581,{ }^{28}$ y $1595 \cdot 1596 .{ }^{29}$ La nobleza indígena no se vio exenta, sufrió los mismos estragos que todos los demás indígenas. Muy pronto y a consecuencia de ello, hacia 1570 varios pueblos ya no contaban con sus representantes tradicionales y muchos ya no sabían nada de su pasado prehispánico. Nuevas generaciones, nacidas en la colonia, estaban a cargo de sus pueblos. Así, las décadas de 1570 y 1580 significaron un periodo de reacomodo en el juego de poder indigena. Muchos pueblos sufrieron la desaparición de sus señores étnicos; unos vieron nacer una nueva elite indigena y otros vieron el ostracismo de sus antiguos señores.

Esto nos muestra, de alguna manera, las modalidades que el mundo indigena utilizaba para hacer frente a la sociedad colonial. Es en este marco que sucedió la historia de los pueblos indios de Nueva España, toda la población vio la transformación de su señorío. Los importantes tlahtocayo se convirtieron en cabeceras, los tlahto-

27 Martínez, Tepeaca, 1984, cap. 4; Pérez Zevallos, "Gobierno", 1982; Quezada, Pueblos, 1993 , cap. 3.

28 Gibson, Aztecas, 1980 , pp. $460-461$.

29 Scholes y Adams (comps.), Moderacion, 1959, pp. 1617. 
que fueron obligados a pagar tributo y los macehualtin encontraron la posibilidad de independizarse.

\section{BIBLIOGRAFIA}

-Bonfil Batalla, Guillermo, "El concepto de indio en América: una categoría de la situación colonial", Anales de antropolo. gía, vol. xx, 1972, pp. 105-124.

-Carrasco, Pedro, "Relaciones sobre la organización social indígena en el siglo XVI", Estudios de cultura náhuatl, vol. vII, 1967, pp. 119-154.

, "La transformación de la cultura indigena durante la colonia", Historia Mexicana; vol. xxv, núm. 98, octubre-diciembre 1975, pp. 175-203.

-Códice Mendieta. Documentos franciscanos, siglos XVT y XVII, Edmundo Aviña Levy, Guadalajara, 1971 (Biblioteca de Facsímiles Mexicanos, 4-5).

- Del Paso y Troncoso, Francisco (comp.), Epistolario de Nueva España, 16 vols., Antigua Librería Robredo de José Porrúa e Hijos, México, 1939-1942 (Biblioteca Histórica Mexicana de Obras Inéditas, 2a serie).

-Farriss, Nancy, Maya society under spanish rule. The collective enterprise of survival, Princeton University Press, Princeton, 1984.

-García-Abasolo, Antonio, Martín Enriquezy la reforma de 1568 en Nueva España, Diputación Provincial de Sevilla, Sevilla, 1983.

-García Icazbalceta, Joaquín (comp.), Cartas de religiosos, Editorial Salvador Chávez Hayhoe, México, 1941.

- (comp.), Códice Franciscano, Siglo $x \eta$, Editorial Salvador Chávez Hayhoe, México, 1941.

- García Martínez, Bernardo, Los pueblos de la Sierra. El poder y el espacio entre los indios del norte de Puebla hasta
1700, El Colegio de México, México, 1987.

-Gerhard, Peter, "La evolución del pueblo rural mexicano (1519-1975)", Historia Mexicana, vol. XxIv, núm. 96, abril-junio 1975, pp. 566-576.

, "Continuity and change in Morelos, Mexico", The Geographical Review, vol. LIv, núm. 3 , julio 1975, pp. 335-352.

-Gibson, Charles, Los aztecas bajo el dominio español (1519-1810), Siglo XXI Editores, México, 1980 (Colección América nuestra, 15).

-Gruzinski, Serge, La colonisation de l'imaginaire. Societés indigènes et occidentalisation dans le Mexique espagnol, XVre-Xvie, Gallimard, Paris, 1988. [La colonización de lo imaginario. Sociedades indigenas y occidentalización en el México español, Siglos XV-XVIII, Fondo de Cultura Económica, México, 1991.]

-Kellog, Susan, "La supervivencia cultural de los indígenas en México central desde 1521 hasta 1600 . Una nueva interpretación", Mesoamérica, 8, 1984, pp. 304-320.

-Martínez M., Hildeberto, Tepeaca en el siglo xV. Tenencia de la tierra y organi. zación de un señorío, Centro de Investigaciones y Estudios Superiores en Antropología Social, México, 1984 (Ediciones de la Casa Chata, 21).

-Pacheco, Joaquín F., Francisco de Cár. denas y Luis Torres de Mendoza (comps.), Colección de documentos inéditos relativos al descubrimiento, conquista y colonización de las posesiones españolas de América y Oceania, 42 vols., Madrid, 1864-1884 .(Facsímil, Vaduz, Nendeln, 1964-1966).

-Pérez Zevallos, Juan Manuel, "El gobierno indígena colonial en Xochimilco (Siglo XVI)", Historia Mexicana, vol. xxxIII, núm. 132, abril-junio 1984, pp. 445-462.

-Quezada Sergio, Pueblos y caciques yucatecos (1550-1585), El Colegio de México, México, 1993.

-Rosenblat, Ángel, La población de América en 1492: viejos y nuevos cálcu- 
los, El Colegio de México, México, 1967 (Centro de Estudios Históricos, 1).

-Ruiz Medrano, Ethelia, Gobierno y sociedad en Nueva España: Segunda Audiencia y Antonio de Mendoza, Gobierno del Estado de Michoacán/El Colegio de Michoacán, Zamora, 1991.

-Saravia Viejo, María Justina, Don Luis de Velasco, virrey de Nueva España (1550-1564), Escuela de Estudios Hispanoamericanos, Sevilla, 1978.

-Scholes, France V., y Eleanor B. Adams (comps.), Moderación de doctrinas de la Real Corona administradas por las órde. nes mendicantes, José Porrúa e Hijos, México, 1959 (Documentos para la Historia del México Colonial, 6). (comps.), Cartas del licenciado Jerónimo Valderrama y otros documentos sobre su visita al gobierno de Nueva España, 1563-1565, José Porrúa e Hijos, México, 1961 (Documentos para la Historia del México Colonial, 7 ).

Spalding, Karen, "Resistencia y adaptación: el gobierno colonial y las elites nativas" $^{n}$, Allpanchis, vol. xvi, núms. 17-18, 1981, pp. 5-21.

Zorita, Alonso de, Breve y sumaria relación de los señores de la Nueva España, Toluca, Gobierno del Estado de México, Gobierno del Estado de México, Toluca, 1974 (Edición conmemorativa de la erección del Estado de México). 


\section{RELACION HISTORICA DE L VIAGE} A LA AMERICA MERIDIONAL $\mathrm{HECHO}$

\section{DE ORDEN DE S. MAG.}

PARA MEDIR ALGUNOS GRADOS DE MERIDIANO

Terreftre, y venir por ellos en conocimiento de la verdadera Figura,

y Magnitud de la Tierra, con otras varias Obfervaciones Aftronomicas, y Phificas:

Por DON JORGE JUAN, Comendador de Aliaga, en el Orden de San Fuan, Socio correppondiente de la Real Academia de las Ciencias de Paris, DON ANTONIO DE ULLOA, de la Real Sociedad de Londres: ambos Capitanes de Fragata de la Real Armada.

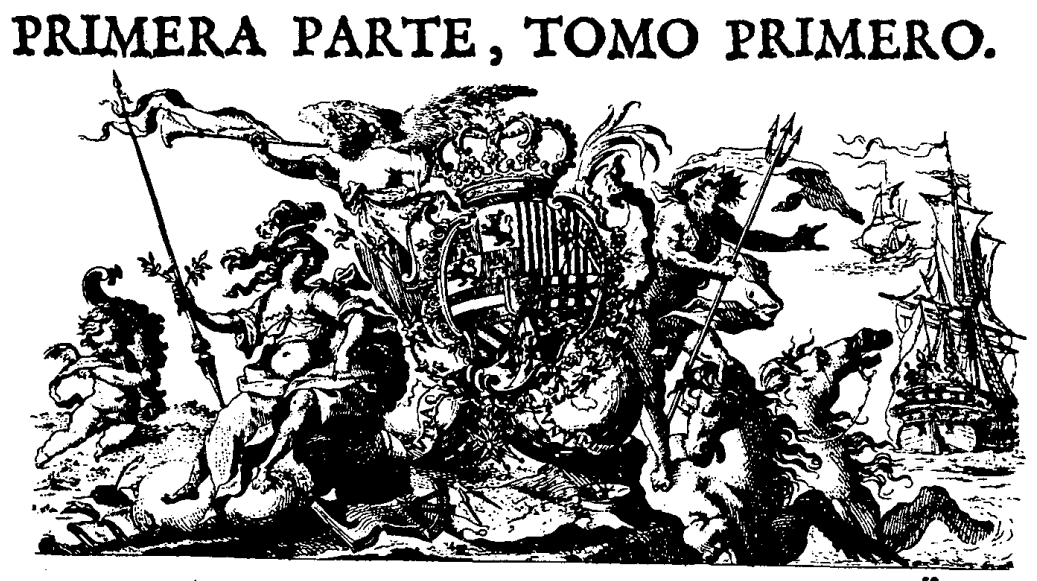

IMPRESSA DE ORDEN DEL REY NUESTRO SEN̂OR E N M A D R I D

Por Antonio Marin , Ańo de M.DCC.XIVIII. 